\title{
ABUSO SEXUAL INFANTOJUVENIL ENQUANTO PROBLEMA SOCIAL EM FORTALEZA, CEARÁ
}

\author{
Irlena Maria Malheiros da Costa* \\ César Barreira * * \\ Luis Silva Barros*** \\ Jackeline S. Jerônimo de Souza ***
}

\begin{abstract}
Neste artigo, descrevemos e analisamos o processo de atuação (enactment) do abuso sexual infantojuvenil como um "problema social" a ser enfrentado pela Rede de Atenção a Crianças e Adolescentes Vítimas de Violência Sexual de Fortaleza, Ceará (Rede). Foram observadas práticas e experiências, sejam coletivas ou individuais, que mobilizam e articulam múltiplos elementos capazes de produzir "casos de abuso sexual" em um Centro de Referência Especializado de Assistência Social (CREAS) da cidade. O termo abuso sexual infantojuvenil está fundamentado na premissa de que a união das sexualidades infantil e adulta é inaceitável e, portanto, abusiva pelo fato de que o objetivo do adulto é obter o próprio prazer sexual. Entretanto, para ser considerado abuso sexual infantojuvenil na Rede, é preciso que a situação sexual seja revelada, denunciada, analisada, tipificada, enumerada e contabilizada, formando ao longo dos atendimentos um dossiê com registros documentais especializados capazes de relatar tecnicamente o acontecimento.
\end{abstract}

PALAVRAS-CHAVE: Abuso sexual. Problema social. CREAS. Enactment.

\section{INTRODUÇÃO}

Especialistas designam como abuso sexual infantojuvenil o fato de crianças e adolescentes serem usados para a satisfação sexual de um adulto. $\mathrm{O}$ conhecimento sobre o fato pode ser dividido em intra-familiar e extra-familiar, a depender da relação estabelecida entre agressor e vítima. Como se sabe, frequentemente, estes fatos envolvem processos de sedução, mas também pode ser imposto através de força física, ameaça e/ou chantagem (UNICEF, 2014). Assim, trata-se de um tipo de violência que "tem sido considerado um grave

* Universidade Federal do Ceará.

Av. da Universidade 2995, $1^{\circ}$ andar, bloco CH3. Benfica. Cep: 60020-181. Fortaleza - Ceará - Brasil. nena.malheiros@gmail.com

http://orcid.org/0000-0002-1275-0875

* * Universidade Federal do Ceará. Departamento de Ciências Sociais.

Av. Humberto Monte, s/n. Bloco 308. Campus do Pici. Cep: 60440-554. Fortaleza - Ceará - Brasil.

cbarreira08@gmail.com

http://orcid.org/0000-0001-5651-9723

* * * Universidade Federal do Ceará. Pesquisador independente. luissbarros2018@gmail.com

https://orcid.org/0000-0002-6730-1444

**** Universidade Federal da Bahia. Programa de Pós-graduação em Ciências Sociais. Estrada de São Lázaro, 197. Federação. Cep: 40.210-730. Salvador - Bahia - Brasil. jack_sjs@hotmail.com

https://orcid.org/0000-0003-2993-4272 problema de saúde pública, devido aos altos índices de incidência e às sérias consequências para o desenvolvimento cognitivo, afetivo e social da vítima e de sua família” (Habigzang et. al., 2005, p. 341).

Considerando a alta incidência e a gravidade das suas consequências, o abuso sexual infantojuvenil tornou-se uma das principais preocupações de órgãos nacionais e internacionais de defesa de crianças e adolescentes, todas amparadas na ideia da criança como sujeito de direitos, e pessoas em condição peculiar de desenvolvimento. Basicamente, interessa às instituições enfrentar esse tipo de violência através de ações articuladas de prevenção, combate ao crime e tratamento dos danos causados às vítimas. À cada instância, são definidas estratégias visando a proteção infantojuvenil, cujas práticas se diferenciam ou se aproximam de acordo com os agentes e as agências. Assim, entendemos que o abuso sexual infantojuvenil está longe de ser homogêneo e pacífico. Seus fundamentos ideológicos estão atrelados a um complexo emaranhado de elementos contraditórios, que ora o fazem existir ora desaparecer nos mais diversos contextos. 
Abandonando a noção de representação, costumeiramente utilizada nas teorias sociais clássicas, esta análise assume como pressuposto teórico-metodológico a ideia de ontologias múltiplas de Annemarie Mol (2002), na qual tende a acentuar-se o caráter múltiplo e complexo da realidade que se revela quando diferentes práticas se ocupam de um mesmo objeto. Para Mol (2002), cada uma das práticas não é simplesmente uma perspectiva distinta sobre um objeto único, mas cada uma delas atua, ou seja, produz uma realidade ligeiramente diferente e nesta produção as coisas não são inertes ou passivas, mas entidades atuantes. A partir dessa perspectiva, o abuso sexual infantojuvenil é visto como múltiplas e diferentes realidades atuadas/performadas que possuem relações entre si. Não se trata, assim, de falar sobre algo único, pré-existente, visto por inúmeras representações, mas de pensar em diversos elementos heterogêneos que são manipulados pelo uso de vários instrumentos no curso das diversas práticas a ponto de transformar uma experiência pessoal ${ }^{1}$ em "problema social” " a ser enfrentado pelo poder público.

O objetivo do artigo é analisar o processo de atuação (enactment ${ }^{3}$ ) do abuso sexual infantojuvenil enquanto "problema social" em um Centro de Referência Especializado de Assistência Social (CREAS) localizado em Fortaleza (CE). Especificamente, a pesquisa procurou

${ }^{1}$ Palavras, expressões e narrativas nativas aparecerão, ao ปิ longo deste artigo, aspadas e em itálico, por envolverem ๙ práticas próprias. Já aquelas com grafia apenas em itálico 今 estão em outros idiomas, ou são palavras que os autores decidiram enfatizar.

ণิ 2

2 A expressão "problema social" é acionada aqui não em - seu sentido sociológico, mas no seu sentido nativo. Diz

F respeito à compreensão coletiva (e reificada) de que inte-

$\because$ rações sexuais envolvendo adultos e crianças/adolescentes

$\therefore$ estão fundamentados em assimetrias de poder, trazendo

Fi consequências nocivas às vítimas, particularmente, e à so-

๓ ciedade, em geral. Assim, o abuso sexual infantojuvenil é

um "problema social" que deve ser enfrentado pelo CRE-

ثิ AS e outros órgãos públicos. O termo também é utilizado como sinônimo de violação de direitos.

${ }^{3}$ Termo utilizado por Annemarie Mol (2002), diz respeito a uma realidade que é feita e atuada (enacted), e não algo simplesmente dado que é descoberto ou observada. É di-

zer que, na prática, os atores humanos e não - humanos

são atuados (enacted). Ao invés de falarmos de algo visto

por inúmeros olhos, a realidade é manipulada (construída)

pelo uso de vários instrumentos no curso de uma diversidade de práticas. mapear as diversas associações que fazem esse tipo de acontecimento existir ou desaparecer na instituição. Aqui, estamos particularmente interessados em mostrar como múltiplas e diversas modalidades de práticas e experiências, sejam elas individuais ou coletivas, desenham e atuam o abuso sexual infantojuvenil, tornando-o um "problema social" a ser enfrentado pelo poder público.

Metodologicamente, a pesquisa foi realizada em um CREAS da capital cearense. As técnicas utilizadas foram a etnografia associada a entrevistas semiestruturadas e análise de documentos

\section{O CENTRO DE REFERÊNCIA ES- PECIALIZADO DE ASSISTÊNCIA SOCIAL (CREAS)}

Localizado em um bairro popular de Fortaleza e ocupando um imóvel térreo grande e climatizado, o CREAS é um equipamento do Sistema Único de Assistência Social (SUAS) e foi criado com o objetivo de desenvolver ações destinadas a famílias e indivíduos em situação de risco pessoal ou social, cujos direitos estão ameaçados ou foram violados. São referidas como violações de direitos as situações de violência física, abandono, abuso sexual, exploração sexual, dentre outras. Trata-se da instituição responsável por atender a uma demanda de 50 bairros e mais de 1.300 .000 habitantes da cidade. Sua gestão cabe à Secretaria de Trabalho e Desenvolvimento Social (STDS), ligada ao Governo do Estado do Ceará, tendo caráter regional por atender também casos de violação de direitos de quatro municípios do interior. ${ }^{4}$ Quando a pesquisa empírica foi realizada, o CREAS era coordenado por uma assistente social. Segundo a instituição, a equipe profissional era composta também por educadores sociais, assistentes sociais, moto-

${ }^{4}$ A criação dos CREAS regionais está prevista no Sistema Único de Assistência Social (SUAS) e dá suporte a municípios que ainda não possuem CREAS municipais. 
ristas, psicólogas, assistentes administrativos, técnicos de assuntos educacionais, advogados, auxiliares de serviços gerais, instrutores de ofício, instrutor educacional, motociclista, pedagoga, perfazendo um total de 140 funcionários internos e externos. A maioria deles (124) possuía vínculo empregatício de colaborador, o qual foi caracterizado por eles como instável e de baixa remuneração.

Quanto à atuação dos profissionais, as assistentes sociais intermediavam o acesso dos usuários à cidadania, ajudando-os a resolver problemas pessoais, familiares e/ou comunitários diante de uma situação de violação de direitos. Já as psicólogas observavam as interações indivíduos-indivíduos, indivíduos-grupos, indivíduos-ambiente social e grupos-ambiente social, lidando mais diretamente com os processos subjetivos, tanto no sentido de identificar fragilidades como em fortalecer a autonomia dos sujeitos em situação de violação de direitos. Os advogados orientavam os usuários diante da necessidade de se recorrer juridicamente para questionar um direito violado, enquanto os educadores sociais exerciam atividades educativas junto aos usuários. Mas quem usufrui, utiliza e participa dos serviços oferecidos pelo CREAS é o usuário, palavra esta que pode se referir tanto a indivíduos quanto a famílias, enquanto os técnicos e os "educadores sociais" são aqueles que atendem aos usuários, estando responsáveis pelos "atendimentos". Os primeiros têm formação superior, realizam atendimento psicossocial ou atendimento jurídico, e ocupam cargo de assistente social, psicólogo ou advogado. Quanto aos educadores sociais, é exigido deles o nível médio de escolaridade e experiência nas áreas da educação ou ciências sociais.

Nestas instituições, os setores de serviço social e de psicologia trabalham juntos diretamente, formando as equipes técnicas, ${ }^{5}$ as quais, por sua vez, são formadas por duplas compostas por assistentes sociais e psicólogas

${ }^{5}$ Durante a pesquisa, as equipes técnicas eram compostas apenas por mulheres, uma situação circunstancial. responsáveis pelos atendimentos psicossociais, atuando em duas frentes: o plantão social $^{6}$ - responsável por fazer todo atendimento psicossocial não programado (demanda espontânea) - e o atendimento psicossocial agendado, que recebe casos agendados previamente (demanda programada). A organização das equipes acontece através de um rodízio de turnos, no qual todas as duplas passam por plantão social e atendimento psicossocial agendado. Os advogados, também ditos técnicos, não fazem parte das equipes técnicas porque atendem apenas quando as duplas entendem que as famílias necessitam de alguma orientação jurídica. Portanto, observa-se que o CREAS tem por finalidade básica atender casos de violação de direitos e suas práticas seguem uma "sequencialidade predefinida" (Valenzuela; Zincke, 2015), comum a todos os casos recebidos, na transformação de experiências pessoais em um "problema social" a ser enfrentado. Entretanto, com a criação de outros CREAS em Fortaleza, que vêm assumindo boa parte da demanda de violação de direitos na cidade, o CREAS aqui analisado atendia principalmente de um tipo de violação de direitos: o abuso sexual infantojuvenil. Este, por sua vez, tem elementos específicos, que ao serem manipulados, entrelaçados e configurados, assumem uma forma particular de violação de direitos. Processo este que trataremos ao longo deste artigo.

Vale ressaltar que todas as ações realizadas no CREAS estão baseadas em normatizações de atendimento psicossocial preconizadas principalmente pelo SUAS, mas não somente nelas, encontrando-se também um conjunto de práticas (Mol, 2002) (re)definidas por acordos negociados nas relações construídas na instituição, da instituição e para a instituição como, por exemplo, nas relações experiência das por usuários e profissionais, em reuniões entre gestores e equipe, em reuniões de equipe ou outras vivências próprias do dia

${ }^{6}$ Os horários de plantão são de 8 às 22 horas, todos os dias (inclusive fins de semana e feriados), também organizada por uma escala de técnicos (há uma equipe técnica diferente por turno de trabalho). 
a dia no trabalho. As decisões definiam como e quando agir, além de quais práticas deveriam ser realizadas na instituição. Assim, o abuso sexual infantojuvenil, longe de ser uma unidade prévia, é uma realização que resulta de um complexo trabalho.

\section{NOTIFICAR: produzindo casos de abuso sexual infantojuvenil de crianças e adolescentes}

Deve-se considerar que toda experiência, seja pessoal/familiar de violação de direitos, por chegar ao CREAS torna-se um "caso de CREAS" através da "notificação". Esta, por sua vez, envolve um conjunto de práticas que atua como um "instrumento disparador de ações" (Lima; Deslandes, 2011, p. 2) capazes de justificar a adoção de medidas de intervenção pública em situações privadas, ao comunicar possíveis ocorrências de violações de direitos às autoridades competentes. As denúncias realizadas no CREAS são ouvidas, analisadas, categorizadas, tipificadas e registradas no "Livro de Notificações"- que consiste em um caderno grande, do tipo brochura, cuja capa dura é etiquetada com o título "Livro de Notificações" e seu respectivo ano. Dentro dele, são criadas à caneta, as tabelas com cerca de doze colunas a serem preenchidas com nome, sexo, idade, telefone, endereço, bairro, motivo etc. no caderno, são numeradas e servem para escrever os dados coletados sobre as denúncias. Por fim, cada denúncia recebe um número de registro e este, assim como outros elementos, sempre referenciará a experiência pessoal/familiar correspondente. É esse processo de registro que transforma a comunicação de um acontecimento específico em denúncia de violação de direitos. Quando as denúncias acontecem no contexto do Setor de Denúncias, seja via disque-denúncia ou encaminhamento de outras instituições, elas são repassadas para que educadores sociais realizem uma espécie de investigação preliminar. Ao receberem a denúncia, eles fazem uma visita domiciliar a fim de levantar maiores informações sobre a situação e observar se esta é um "problema social", identificando se a denúncia procede ou não.

Um dos educadores sociais mais experientes do CREAS chama-se Francisco ${ }^{7}$ (51 anos) e atua como educador social na instituição desde sua fundação. Com vasta experiência na área de assistência social de crianças e adolescentes, devido ao trabalho realizado desde 1992, suas principais atividades profissionais são exercidas fora dos muros do CREAS, seja identificando possíveis violações de direitos nas ruas de Fortaleza ("busca ativa") ou na residência de determinadas pessoas através da visita domiciliar. Independente do contexto, se público ou privado, Francisco conversa com pessoas, observa comportamentos, analisa situações e toma decisões sobre possíveis intervenções públicas no "caso". Às vezes, ele procura o auxílio de outros agentes públicos como policiais, médicos, assistentes sociais, psicólogos e conselheiros tutelares. Em outras, mantém-se na posição de "observador de realidades", já que existem limites legais (e "seguros") para o seu trabalho. De uma forma ou de outra, sempre que Francisco volta ao CREAS, toda sua experiência de trabalho é registrada em forma de relato escrito para que aquelas supostas violações de direitos encontradas em suas observações se tornem "problemas sociais" a serem enfrentados.

A atividade mais realizada por Francisco, diante de uma denúncia de abuso sexual infantojuvenil, é a visita domiciliar que acontece da seguinte forma: um carro leva o educador social - às vezes acompanhado de técnicos - à residência da "suposta vítima" a fim de avaliar condições de vida e identificar situações de violência. Chegando ao local sem aviso prévio, ele observa, pergunta e anota informações. De acordo com ele, dificilmente há receptividade na família visitada, já que muitas vezes as denúncias

${ }^{7}$ Suprimimos nomes ou utilizamos nomes fictícios a fim de preservar a identidade dos interlocutores. 
de abuso sexual infantojuvenil são permeadas pelos "segredos de família" (Costa, 2013). Sabendo disso, o educador social utiliza-se de sua "experiência profissional" e do "conhecimento adquirido” em cursos de capacitação para identificar no contexto da visita "sinais" de que há algo acontecendo (e que não deveria acontecer) naquela família. Esse tipo de experiência e ou conhecimento adquirido remete ao conceito de Ingold (2010) elabora sobre a educação da atenção. Ingold aponta que não aprendemos a partir de uma série de representações que absorvemos em nossas mentes e aplicamos no mundo, invés disso aprendemos no engajamento com o mundo, no ambiente do qual estamos inseridos. Essa noção é fundamental para compreendermos esse saber dos profissionais que trabalham no CREAS como um processo de aprendizagem que está imbricado no saber que perpassa pelo corpo, ambiente e ambos estão imersos em um contexto de engajamentos práticos no mundo do qual habitamos.

Durante a visita, o educador social afirma que observa a "reação" de cada membro da família, especialmente da "suposta vítima". "A vítima do abuso fica cabisbaixa, [...] fica receosa de falar, não fala”, revelou Francisco. São feitas, também, várias perguntas: se as crianças da casa frequentam a escola; quem mora na casa; quem sustenta a família; com quem a criança costuma ficar; quais lugares ela frequenta e com quem; ou se a criança costuma ficar sozinha com alguém, dentre outras. Todas as respostas (e a reação das pessoas a cada pergunta) são anotadas de forma a, posteriormente, comporem um relatório sobre aquela visita. Em nossa conversa, Francisco ressalta inúmeras vezes que nenhum educador social pode retirar a criança da família, mesmo percebendo maus-tratos, pois, legalmente este não é seu papel. Ao mesmo tempo, ele disse que é possível "convidar" aquela a família a frequentar um serviço de atendimento psicossocial e incentivar a "suposta vítima" a fazer uma denúncia na polícia, caso seja necessário. Na sequência, após a visita o educador social preenche o re- gistro de ocorrência com aquele já referido número de registro, bem como informações sobre a "suposta vítima" e sua família. Além disso, ele escreve um relatório, descrevendo as condições de vida da família e narrando suas impressões: "a gente coloca [...] o semblante do cara 'né', [...] como ele tava, de como ele olhava, a gente colocava as características do usuário, né”, relatou Francisco. Concluído o relatório, ele é arquivado e envia-se uma solicitação para que um funcionário do próprio CREAS telefone para a família marcando o atendimento psicossocial com uma equipe técnica.

Como as denúncias também acontecem quando uma pessoa vai espontaneamente ao CREAS comunicar a ocorrência de algum tipo de violação de direitos, nesses casos, o atendimento inicial é feito no plantão social, em sala específica. Cabe ao plantão social atender toda a demanda espontânea. Em geral, esta pode ser de três tipos: a) queixa de desaparecimento, b) comunicação espontânea de alguma violação de direitos, e c) pessoa encaminhada de outras instituições. O trabalho é realizado por equipe técnica plantonista e consiste em escutar a demanda de cada usuário, analisar as informações coletadas, categorizar o problema comunicado, decidir que ações devem ser realizadas para resolvê-lo, orientar o usuário sobre a questão e os caminhos a serem seguidos, registrar (registro de ocorrência) a ocorrência de violação de direitos. Concluído o atendimento inicial, as plantonistas solicitam ao educador social de plantão que registre aquele "caso" no "Livro de Notificações" e cadastre a denúncia no sistema. Em "casos" específicos envolvendo crianças e adolescentes, a equipe técnica plantonista também preenche uma ficha de atendimento contendo: número do registro, data, motivo da denúncia, além de dados gerais da "suposta vítima" e sua família, que servirão de referência para outras práticas que porventura sejam realizadas.

Existem pelo menos dois circuitos através dos quais as notificações são feitas: aquele produzido por denúncias presenciais e aquele 
produzido por denúncias não-presenciais. Em ambas as situações, observamos a formação de uma série de práticas envolvendo produção de documentos através das quais experiências pessoais são transformadas em "casos de abuso sexual". Com o "caso" pronto, a equipe técnica faz uma nova análise, voltando aos referentes motivos da denúncia (desaparecimento, violência, busca de orientação etc.) e endereço da família (territorialização). Tais elementos são utilizados para se determinar uma nova tipificação: se é "Caso de CREAS" ou "não é caso de CREAS". Aqui, sendo um "caso de abuso sexual", e se esse "caso" foi revelado no (ou para o) CREAS, e se a família da "suposta vítima" mora na abrangência territorial ${ }^{8}$ da instituição, a equipe técnica entenderá aquela situação como um "Caso de CREAS", registrará todas as informações pertinentes nos instrumentais burocráticos do CREAS e agendará um atendimento psicossocial na própria instituição, transformando a criança/adolescente (e sua família) em usuária do serviço "por direito". ${ }^{9}$ Por outro lado, se não for "Caso de CREAS", a equipe técnica encaminha o "Caso" para a(s) instituição (ões) que poderá(ão) suprir as necessidades dos envolvidos e, se houver necessidade, escreve um relatório circunstancial a ser enviado à entidade destinatária.

Concluída a notificação, os dados alimentam um banco de dados digital e, quantificados, são mensalmente enviados à STDS, via $\overrightarrow{\tilde{N}}$ internet. "Quando reunidas de forma sistemaN. tizadas, as notificações passam a compor sisteô mas de informações próprios, que possibilitam ¿ o acompanhamento, de forma mais ampla, das características do fenômeno estudado, quan$\dot{\mathrm{i}}$ to à sua distribuição e tendências" (Teixeira, ले 1998, p. 9). Aqui não importa mais as especi$>$

5 ${ }^{8}$ Refere-se ao recorte territorial que define o público a ser atendido pelos serviços socioassistenciais, definidos de acordo com áreas de abrangência definidas pelo Estado. Ver Territorialização, em Belo Horizonte, 2007, p. 11.

${ }^{9}$ De acordo com as técnicas entrevistadas, ninguém é obrigado a ser usuário do CREAS, pois o serviço é um direito e não um dever. Isso é o que elas chamaram de "princípio da autonomia”. Assim, quando um usuário do serviço desiste do atendimento, é feito um relatório e arquivado o prontuário. ficidades das experiências pessoais/familiares, mas apenas o resultado das múltiplas inscriÇões ${ }^{10}$ (Latour, 2002) que transformaram narrativas pessoais em números de casos. Estes, por sua vez, formarão uma tabela que posteriormente será divulgada no site oficial da STDS. Tais informações produzidas também poderão orientar decisões no sentido de, por exemplo, planejar futuras ações, melhorar a gestão, elaborar novos modelos de ação e supervisionar a execução de práticas.

Vimos, ao longo desta seção, mostrando como uma experiência pessoal transforma-se em um "caso de abuso sexual" no CREAS. Trata-se de um processo de registros de narrativas e práticas, cujos modos de inscrição envolvem papeis timbrados, computadores, impressoras, carros, listas, fichas, cadernos, anotações, canetas, pessoas, formações, cursos etc. São procedimentos que, em geral, permitem que tais experiências sejam examinadas, mensuradas, comparadas, combinadas, desdobradas em estatísticas, investigações criminais, relatórios, pesquisas científicas. Os processos descritos fazem com que o abuso sexual infantojuvenil exista enquanto "problema social" a ser enfrentado e, se por algum motivo aconteçam práticas diferentes, é possível que os fluxos mudem e a criança/adolescente não seja atendida, por exemplo.

\section{ATENDER: o acompanhamento de famílias de crianças e adolescentes vítimas de abuso sexual infantojuvenil}

Ao chegarem ao CREAS, quem "acolhe" primeiramente os usuários é a recepção, estando suas ações orientadas pelo tipo de deman-

10 Inscrições (ou referência circulante) trata-se de um conceito trabalhado por Bruno Latour (2002) quando ele descreve o trabalho de cientistas na floresta amazônica. Para ele, o conhecimento produzido pode circular por diferentes etapas, abrangendo circuitos muito mais amplos e permitindo, assim, o estabelecimento de relações mais duradouras entre atores como cientistas, financiadores e realidades empíricas. Neste artigo, entendemos que as narrativas pessoais, através das técnicas utilizadas no CREAS, vão se transformando em "casos de abuso sexual". 
da, as escalas de trabalho da equipe técnica e as agendas. A identificação de todos os " $\mathrm{Ca}$ sos" é anotada em um caderno específico, bem como os funcionários que os atenderão. Registrada a presença do usuário, este é orientado a aguardar na sala de espera, que é composta por cadeiras de plástico brancas e uma televisão. Acomodados, os usuários aguardam ali uma equipe técnica chamar para o atendimento, seja do plantão social ou do atendimento psicossocial agendado. Ao ser agendado para o atendimento psicossocial, o "caso" é imediatamente colocado sob a responsabilidade de uma equipe técnica. "O primeiro atendimento sempre é junto com o assistente social [...]. E a partir do segundo atendimento, se a gente sentir necessidade, eu atendo a criança ou o adolescente e o assistente social atende a família”, afirmou Marisa (psicóloga, 52 anos). No primeiro contato, psicóloga e assistente social entrevistam juntas criança/adolescente (e sua família), na tentativa de conhecer melhor o contexto familiar, condições de vida e motivos pelos quais o "caso" foi encaminhado para a instituição. Esse levantamento fornece subsídios para que a equipe técnica responsável trace um plano de atendimento, tendo como objetivo o "fortalecimento dos vínculos e empoderamento familiar", explicou Sabrina (assistente social, 37 anos).

Com o objetivo de fortalecer vínculos dos usuários, a equipe técnica inicia o acompanhamento familiar, o qual por sua vez, acontece através da "articulação da Rede" e de ações que visam esclarecer e orientar os usuários sobre seus direitos. O início do acompanhamento é marcado pela abertura de prontuário, que consiste em um conjunto de folhas de papel, nas quais estão registrados em linguagem escrita e técnica, os dados gerais sobre os usuários. Desde os primeiros contatos da família com o CREAS, cada atendimento é registrado textualmente à caneta, em folhas de evolução. Ao final do registro, as folhas preenchidas são carimbadas, assinadas e datadas pelas técnicas responsáveis. São anexados também ficha de atendimento, registro de ocorrência, relatórios psicossociais, relatórios circunstanciais e cópias de encaminhamento emitidos e/ou recebidos pela instituição. Tais práticas vão formando, aos poucos, uma espécie de dossiê sobre o "caso".

No atendimento psicossocial agendado para "casos de abuso sexual", crianças/adolescentes (e suas famílias) - que já tiveram acolhimento inicial e receberam visita domiciliar de educadores sociais - frequentam o CREAS em data e horário previamente agendados para atendimento com uma equipe técnica. Por convenção, cada equipe atende 6 famílias por dia, com hora marcada, seguindo o horário comercial e revezando-se em duas salas. Devido à grande demanda, a frequência de atendimentos é geralmente mensal, durando cerca de uma hora cada. Vale ressaltar que muitas famílias faltavam o atendimento. $\mathrm{O}$ atendimento psicossocial é "um procedimento de escuta e identificação de demandas do usuário, viabilizando a realização das intervenções pertinentes aos serviços da Política de Assistência Social" (Alagoas, 2010, p. 3). Isso significa que psicólogos e assistentes sociais se utilizam cada um na sua área - de conhecimentos técnicos, decidindo os rumos do atendimento a depender do "Caso". No CREAS, são observados/avaliados: o subtipo de abuso sexual (intrafamiliar ou extrafamiliar), a idade da "suposta vítima" quando ocorreu o fato narrado, a idade da "suposta vítima" no dia do atendimento, quem é o "suposto agressor", o impacto da experiência vivenciada na saúde biológica e mental, a reação da família diante da revelação do abuso sexual, a estrutura/organização familiar, a situação socioeconômica, o território no qual está localizada a residência da "suposta vítima”. A observação/avaliação técnica materializa-se através da utilização de instrumentos técnico-operacionais, como entrevistas individuais, entrevistas em grupo/família, aplicação de questionários, visitais domiciliares, preenchimento de fichas, prontuários e folhas de evolução, emissão de relatórios (Gerber, 2011). Apreendidas todas as informações necessárias, 
a equipe técnica faz um plano de atendimento para a família, "que detalhará o processo interventivo profissional do/a assistente social para responder as demandas da instituição à qual está inserido/a" (Gerber, 2011, p. 1). E, conjuntamente com a família, traça um plano de enfretamento à situação vivenciada.

Geralmente, crianças/adolescentes que frequentam o CREAS vão acompanhados(as) da mãe ou da avó, que aparecem no prontuário como "pessoa de referência na família". Após o primeiro contato, assistentes sociais e psicólogas atuam em salas separadas na maioria dos atendimentos: as primeiras entrevistam a família na pessoa da mãe/avó/responsável; e as segundas, atendem crianças/adolescentes. Trata-se de intervenções diferentes que se pretendem complementares, sendo as psicólogas interessadas em trabalhar e orientar crianças/ adolescentes em questões subjetivas relacionadas ao abuso sexual sofrido (e suas repercussões emocionais) e as assistentes sociais avaliam e orientam a família no enfrentamento cotidiano ao "problema". Essa divisão ocorre devido ao tipo de trabalho proposto pelo CREAS e à reivindicação de algumas psicólogas para que se observasse melhor o sigilo profissional em algumas situações de atendimento.

Oficialmente, no CREAS, todos os membros das equipes técnicas são responsáveis por executar serviços, programas, projetos e benefícios, sem diferenças de formação profissional.

సิ As Assim, psicólogos, assistentes sociais e advo$\sim$ gados tendem a realizar as mesmas práticas de \% trabalho e, ao mesmo tempo, espera-se deles ¿ olhares especializados próprios de cada pro$\overrightarrow{7}$ fissão. Com a pretensão de ser interdisciplinar, $\dot{2}$ esse modo de trabalho - que ora amplia olhares î ora os especializa - trouxe consigo alguns desafios, já que as profissões carregam em si particularidades. Como atender as demandas integral e interdisciplinarmente sem ultrapassar os limites impostos por cada profissão? Como conciliar diferentes aportes político-teórico-metodológicos sem que uma disciplina colonize outra(s)? Como é possível psicólogos e ad- vogados realizarem atividades historicamente ligadas à formação em serviço social.

De certa forma, o ambiente de trabalho do CREAS refletia essas dúvidas. Havia nas narrativas dos interlocutores uma espécie de tensão em torno dos limites e possibilidades de um atendimento interdisciplinar, especialmente nas fronteiras entre assistentes sociais e psicólogas. Vejamos o que falou Gerusa:

[O trabalho interdisciplinar] é difícil. Porque, assim, por mais que a gente escute ser necessário... Todo mundo tem o mesmo discurso: "ah, tem que ter o trabalho interdisciplinar e tal. Mas na hora do fazer é difícil, né? [...] Então, aquela dupla vai atender aquela família. Então, o atendimento é feito casado, junto. E, aí, o assistente social faz o que compete a ele e o psicólogo, o que compete a ele. Mas ainda é... Tem muita resistência de alguns... de alguns profissionais [...]. A dificuldade de saber: "ah, eu posso entrar no atendimento?” [...] Porque como a gente atende muito criança, alguns assistentes sociais [...] falam que não acham certo entrar no atendimento na sala junto com o psicólogo pra atender a criança, né? Outros já acham que não, que tem que atender [junto] sim. [...] Na faculdade, também estudaram e trabalharam e sabem lidar com isso, com a criança. Então, havia muito essa discussão, né. Então, assim, é, cabe da dupla tá conversando, verificando, né. O que é que é necessário praquela família naquele momento? [...] Porque existem, né, as restrições, assim pra o atendimento. Se a psicóloga perceber a necessidade de tá conversando com aquela mãe, ou tá conversando com aquela criança, sozinha, né? Porque percebeu que aquela mãe tava muito fragilizada e talvez ela sozinha seria melhor pra tá falando...É uma conversa que você vai ter com sua dupla assistente social e explicar: "olha, deixa eu ficar sozinha?! Depois eu te repasso o que couber, né, da situação”. E aí é que se entra o planejamento. Que é o planejamento que vai ser feito com aquela família. [...] Você atende e conversa depois: "e aí? O que a gente vai fazer?” Porque ficou muito atendimento por atender, sabe? No começo. Eu, quando eu entrei aqui, eu sofri horrores! [risos] Porque eu não entendia como era meu trabalho. Eu não sabia o que é que eu tinha que fazer. Porque eu sou psicóloga, mas não sou psicóloga clínica aqui dentro. Sou uma psicóloga que tô aqui pra dar um apoio. Então, assim, a psicologia clínica tem um espaço específico. Uma outra forma de abordagem. [...] Algumas pessoas não tinham esse entendimento, né. E acabava 
fazendo psicologia clínica aqui dentro, que não é. [...] (Psicóloga, 29 anos).

A dificuldade de implementação prática da interdisciplinaridade no CREAS ficou muito evidente em todas as entrevistas com assistentes sociais e psicólogas. Por um lado, havia um consenso quanto ao papel exclusivo do serviço social: a elaboração de relatórios sociais e a supervisão direta de estagiários graduandos em serviço social. Ao mesmo tempo, sempre, de uma forma ou de outra, uma questão surgia: o que (não) faz um psicólogo nos CREAS? Como elaborar um relatório psicossocial? E dessas questões, surgiam desdobramentos: a) que técnicas próprias do trabalho de psicólogo (não) podem ser aplicadas na assistência social?; b) (não) é possível realizar escuta psicológica em instituições socioassistenciais?; c) o que (não) é sigilo profissional? Um problema recorrentemente descrito, por exemplo, foi uma possível "confusão" que alguns psicólogos faziam entre atendimento psicossocial e atendimento clínico. Aqui encontramos um consenso nas narrativas: "o CREAS não é clínica". Do consenso entre as entrevistadas, listavam-se pelo menos três motivos: a) a demanda do CREAS é muito grande; b) não existe tempo hábil para fazer clínica; c) a clínica deve ser serviço oferecido pelo Sistema Único de Saúde (SUS). Esses limites significam na prática que: a) o hiato entre os atendimentos deve ser de, pelo menos, um mês (salvo exceções); b) todas as demandas indicadas para psicoterapia devem ser encaminhadas. Por outro lado, parecia consenso também a competência exclusiva das psicólogas para a avaliação psicológica e a supervisão de estagiários graduandos em psicologia.

O problema da interdisciplinaridade desencadeou discussões e estas geraram rodas de conversa durante as reuniões de equipe. De acordo com psicólogas e assistentes sociais entrevistadas, apesar de sempre resgatarem esse assunto, a tensão desencadeada pela "confusão" entre atendimento psicossocial e atendimento clínicos e dissipou quando foram cria- das as equipes técnicas, possibilitando maior diálogo entre os saberes diante de cada "Caso" mesmo com a questão permeando todas as narrativas. Com as equipes, resolveu-se também o problema da sobrecarga de trabalho de assistentes sociais diante de relatórios (agora chamados de relatórios psicossociais), análises socioeconômicas e encaminhamentos socioassistenciais. As ações passaram a ser "conversadas", "feitas em conjunto". Aliás, nem todas.

A psicologia tem o sigilo profissional como um fundamento ético quase que intransponível e esse assunto gera ainda mais tensões no CREAS. Na etnografia, tivemos notícias de que, alegando necessidade de garantir o sigilo profissional, algumas psicólogas exigiram que o atendimento e a avaliação psicológicos fossem realizados em sala separada, sem a presença de assistentes sociais. Essa exigência desencadeou discussões sobre a natureza do sigilo profissional: o sigilo profissional do psicólogo e o direito à confidencialidade dos usuários seriam resguardados se o atendimento psicológico contasse com a presença de assistentes sociais? Pareceu-nos que tais discussões não chegaram a um consenso. O problema da interdisciplinaridade persistia. As opiniões se dividiram nas reuniões de equipe e a situação foi aparentemente resolvida deixando para cada equipe a liberdade em decidir como seriam realizados os atendimentos. Na prática, o que observamos foi que as psicólogas adquiriram liberdade (às vezes contestada) de decidir quando atender um usuário sem a presença de outros profissionais e cabia às assistentes sociais atenderem familiares.

No CREAS, o atendimento psicológico consiste em coleta de dados, análise da situação e intervenção técnica. Para tanto, são desenvolvidas atividades de escuta psicológica e orientação, geralmente individuais, capazes de identificar fragilidades subjetivas e orientar usuários (e seus familiares) na criação, fortalecimento e potencialização de vínculos afetivos e sociais. Então, o que diferencia o trabalho de psicólogos e assistentes sociais no SUAS? Acreditamos que um elemento-chave é o trei- 
namento dos corpos, durante a formação profissional, no sentido de "aprender a ser afetado" proposto por Latour (2008, p. 40).

A psicologia no CREAS trouxe consigo novas ferramentas para o enfretamento dos "problemas sociais", fazendo emergir a noção de subjetividade como fator importante. Através de um aporte político-teórico-metodológico próprio, os psicólogos utilizam técnicas de avaliação e intervenção aprendidas durante sua formação profissional. Aqui, estamos falando do que Latour (2008, p. 42) chamou de "corpos que aprenderam a ser afetados por diferenças que anteriormente não podiam registrar, através da mediação de um arranjo artificial"; ou seja, algumas pessoas tornaram-se estudantes no curso de graduação em Psicologia e, ao longo desse período, seus corpos foram aprendendo de forma sistemática novas formas de habitar o mundo. É como se elas adquirissem novos sentidos e, por isso, costumam ver coisas que outros profissionais não veem. Um exemplo disso é a escuta psicológica, como se na prática psicólogos tivessem adquirido um "novo órgão" capaz de identificar "demandas psicológicas".

Entretanto, segundo Hadler e Guareschi (2012), muitos psicólogos não vivenciam, durante sua formação, a experiência de uma formação adequada para atuar na área de assistência social, não conhecendo suas especificidades e exigências cotidianas ${ }^{11}$. Em consequência, muitos psicólogos chegam aos serviços নิ de atendimento psicossociais sem conheci․ mento sobre a política pública que os embasam, "sem ter uma postura ético-política clara, sem entender o trabalho transdisciplinar. Che今 ga[m] conhecendo apenas práticas cristaliza$\dot{2}$ das, baseadas no modelo clínico, que pouco க் (ou nada) contribuem para a intervenção co$\overrightarrow{~ m u n i t a ́ r i a ” ~(C o r d e i r o ; ~ S a t o, ~ 2017, ~ p . ~ 42) . ~ E i s ~}$ um grande desafio destacado pelas psicólogas do CREAS: aprender novas formas de realizar atendimento psicológico.

${ }^{11}$ Apesar da assistência social empregar aproximadamente 9\% dos psicólogos registrados no Brasil (Cordeiro e Sato, 2017).
Outra questão repetidamente levantada pelas profissionais da psicologia é a precarização do trabalho. Com seus vínculos empregatícios fragilizados e influenciados por questões políticas e baixos salários, as psicólogas entrevistadas (especialmente as mais jovens) explicaram que seus trabalhos na assistência social eram temporários, um "lugar para passar a chuva" até elas encontrarem melhores empregos ou estabilizarem suas clínicas particulares. Essa parece ser uma tendência nacional na área de assistência social, o que prejudica o atendimento de usuários nos centros de referência de todo país (Cordeiro; Sato, 2017).

Por outro lado, não podemos negar os esforços internos em busca de uma construção de práticas psicossociais interdisciplinares que transformaram o trabalho da psicologia no CREAS ao longo dos anos. $\mathrm{O}$ atendimento das psicólogas entrevistadas acontecia através do olhar treinado sobre: a) o estado psicológico dos usuários, identificando, por exemplo, sintomas de sofrimento e/ou de distúrbios psicopatológicos; b) as relações estabelecidas entre indivíduos, famílias, grupos, comunidades; c) as potencialidades pessoais, familiares, grupais, comunitárias. Vale ressaltar que, também em termos práticos, esse processo se diferencia do atendimento psicológico clínico, podendo acontecer através de um encontro entre a psicóloga e o usuário (em grupo, grupo familiar ou individualmente) em sala reservada ou de uma atuação conjunta de psicóloga e assistente social com o usuário.

Geralmente, os atendimentos psicológicos no CREAS costumam ser individuais e são realizados pelas psicólogas na sala de atendimento. Em casos envolvendo criança, esta é levada para a sala lúdica, onde ficam brinquedos à disposição. Já o adolescente é atendido na sala de atendimento, mas também separado dos adultos. De qualquer forma, nos atendimentos, as psicólogas costumam observar a sintomatologia através de uma escutada criança/adolescente (Dorme bem? Como se sente? É agressivo? Age com apatia?), dinâmica familiar 
(Com quem mora? Quem cuida? Como se estabelecem as relações familiares?), comportamento na escola (aprendizado, relações com pares) etc. Com base nas respostas da criança/ adolescente e na observação técnica do encontro terapêutico, a psicóloga avalia e decide como intervir, a depender do caso. Entretanto, quando a "suposta vítima" apresenta necessidade de intervenção psicoterapêutica (atendimento psicológico clínico), ela é encaminhada a serviços de atendimento psicológico oferecidos por clínicas-escola de faculdades de psicologia de Fortaleza. ${ }^{12}$

No mesmo dia, enquanto a psicóloga atende a criança/adolescente, a assistente social da equipe permanece com a família em outra sala. No CREAS, os atendimentos socioassistenciais são ações interventivas desenvolvidas com o usuário e conduzidas por uma assistente social. Na mesma lógica das psicólogas, as assistentes sociais também tiveram um treinamento durante sua formação profissional, o que produz uma forma específica de estar no mundo e esse estar no mundo aparece, por exemplo, em outro tipo de escuta, uma escuta socioassistencial.

Os atendimentos da assistente social desenvolvem um trabalho de identificação e intervenção diante de conflitos familiares e/ ou comunitários, sofrimento familiar, dificuldades socioeconômicas, bem como na reorganização da dinâmica familiar. Aqui, além das relações entre indivíduos, indivíduos e grupos, há também uma relação entre indivíduos/grupos e o Estado no sentido de garantia de direitos previstos por lei. Com esse tipo de intervenção, espera-se que o usuário desabafe, dialogue e, principalmente, receba as orientações técnicas sobre direitos sociais.

O principal instrumento utilizado pela equipe técnica nos atendimentos psicossociais

12 Todos os entrevistados afirmaram que não há instituições públicas em Fortaleza que ofereçam serviço de psicoterapia para casos leves e médios. Por isso, são as clínicas-escola das faculdades de psicologia que recebem essa demanda. Os casos considerados graves e crônicos são encaminhados para os Centro de Atenção Psicossocial (CAPS). Em ambos os casos, não há vagas e há listas de espera. agendados é a entrevista. Esta configura-se no CREAS de forma semelhante à descrita por Gerber (2011, p. 10): durante o atendimento tanto a assistente social como a psicóloga vão "concomitantemente elencando possíveis situações para intervir nas questões/demandas postas pelo entrevistado. Neste sentido, o objetivo da entrevista é conhecer a situação do usuário, para que possa dar prosseguimento do processo e construção interventiva".

De acordo com uma psicóloga, na entrevista psicossocial, observa-se o tom de voz da pessoa entrevistada; expressões verbais podem mostrar a aceitação da palavra da criança/ adolescente ("ela [mãe] chama, por exemplo, a pessoa de filho? Ou filha? Ou chama de 'aquele menino' ou 'aquela menina'?”); interesse em resolver ("aquela pessoa vem dizer: 'eu quero saber dos meus direitos, quero saber quem procurar"; ou "aquela pessoa tá me dizendo: 'ah, olha, eu não tava presente, disseram que aconteceu isso, talvez tenha acontecido isso'”; ou 'ah, não, é muita coisa, é muito lugar, é muito longe”'); e o estado dos vínculos familiares e comunitários ("aquela família tem contato com seus membros mais próximos, que aquela vítima vai poder contar como o apoio, ou se não da família de um vizinho ou vizinha?”; ou "é uma família que só conta com aqueles dois ou três membros? Que pode ser uma família mais fragilizada"). Assim, é através da entrevista que os casos são conhecidos e avaliados para, então, sofrerem algum tipo de intervenção que pode ocorrer na própria entrevista em curso através de orientações e produção de encaminhamento sou posteriormente, após a avaliação da equipe técnica.

Após cada atendimento psicossocial realizado, a equipe técnica se reúne, discutem o "caso" e descrevem resumidamente o atendimento em folhas de evolução, anexando-as ao prontuário.

Enquanto as equipes técnicas atendem diariamente usuários, o trabalho dos advogados contratados para o CREAS é apenas "consultivo”, não participando direta e frequentemente 
dos atendimentos, explicou Jonas (advogado, 32 anos). A figura do advogado surge no âmbito das políticas socioassistenciais brasileiras como peça estratégica na garantia de direitos fundamentais e visa contribuir para "o exercício da cidadania pelos cidadãos, principalmente os mais vulneráveis, através da viabilização do acesso aos direitos sociais, direitos socioassistencias e outros, que já estejam e/ou venham a ser regulamentados, através da prestação de serviços públicos” (Flores, [2015], p. 11).

Segundo Flores ([2015], p. 11), o advogado é o "operacionalizador do 'Direito à Assistência Social"'. Entretanto, a atual normatização dos serviços socioassistenciais no Brasil é pouco clara quanto às práticas do advogado no contexto do CREAS. Por outro lado, ainda de acordo com Flores ([2015], 14), as orientações técnicas preveem que o trabalho do setor jurídico "consiste na orientação e nas possibilidades de intervenção judicial, na elaboração e no acompanhamento de peças judiciais".

Já nas práticas realizadas no CREAS, o atendimento jurídico é apenas uma orientação aos usuários sobre seus direitos e encaminhamento a instituições públicas que compõem o Sistema de Justiça Criminal. Não há, assim, elaboração ou acompanhamento de investigação criminal, peças judiciais ou participação em julgamentos. Não há também a atuação dos advogados no atendimento direto de usuários nem orientação coletiva (como a realização de సี palestras sobre direitos do cidadão, por exemㄱ. plo). Às vezes, quando solicitados pelas técni\% cas, os advogados saem em busca de informa¿ ções na delegacia ou vara criminal, mas sem 今 qualquer intervenção no caso. O trabalho é re¿. alizado na sala do setor jurídico, onde podem if ser procurados sempre que houver necessidade de alguma orientação jurídica (um exemplo comum é informar sobre a medida protetiva diante das ameaças do agressor: quem e onde procurar para fazer o pedido). Quando isso acontece, ou o usuário é encaminhado ao setor jurídico ou o advogado é chamado para comparecer à sala de atendimento. Vale ressaltar que nenhum dos familiares com quem tivemos contato na pesquisa sabia que existiam advogados no CREAS.

Dois são os motivos destacados pelos advogados entrevistados para justificar o caráter restrito da atuação do setor jurídico no CREAS: a) há serviços públicos de atendimento jurídico (como Ministério Público e Defensoria Pública) os quais são responsáveis por atender as pessoas e representá-las caso necessário; b) o salário pago aos advogados do CREAS é muito baixo para que eles atuem para além da prestação de uma consultoria jurídica pontual.

Quando não estão em atendimento, as equipes técnicas trabalham na elaboração de fichas, folhas de evolução, estatísticas, registros de atendimentos, relatórios, além da organização da agenda e outras atividades burocráticas. Cada atendimento realizado (ou não) gera informações que serão registradas em papeis timbrados e, como documentos, poderão circular interna (no próprio CREAS, de um setor para outro) e/ou externamente (envolvendo outras instituições) de forma a desencadear novas informações a serem também documentadas. É nesse movimento que são produzidos, por exemplo, os relatórios psicossociais que comporão o inquérito policial e/ou o processo judicial, as estatísticas de atendimentos enviadas para órgãos reguladores, gestores, pesquisadores, as listas de visitas domiciliares, dentre outros.

O acompanhamento dos casos no CREAS pode acabar por: a) decisão do usuário; ou b) decisão da equipe técnica. A decisão dos usuários quanto ao fim do atendimento pode ser percebida pela equipe técnica tanto como abandono quanto como um exercício da própria cidadania através de uma decisão consciente do que é melhor para si mesmo e para a família. Observamos que, nas narrativas, tais percepções não são necessariamente excludentes. Em resposta à decisão, a equipe técnica tenta remarcar os atendimentos por três vezes (padrão), realiza uma visita domiciliar para avaliar a situação da criança/adolescente (e da família), escreve um relatório final sobre 
o caso e arquiva o prontuário. É importante notar que identificar a liberdade (e não a obrigatoriedade do serviço) do usuário não significa que a equipe técnica concorde e, nestes casos, o relatório deverá conter impressões a esse respeito. Outra forma de pôr fim ao acompanhamento acontece quando a equipe técnica analisa o “caso”, entende que a família já está "fortalecida" e decide que a intervenção do CREAS pode ser concluída. Nestes casos, faz-se um atendimento final, escreve-se um relatório finale arquiva-se o prontuário.

\section{RELATAR: a produção de abuso sexual em documentos}

A elaboração de relatórios é uma prática muito comum no CREAS. Eles são instrumentos de comunicação intra e interinstitucional, através dos quais são relatadas detalhadamente informações relevantes sobre um "caso". A necessidade de se emitir um relatório pode acontecer em, pelo menos, três situações: a) se a equipe técnica entender que há a necessidade de elaborar relatório ao realizar o encaminhamento de um “caso” (solicitação de psicoterapia, por exemplo); b) após visitas domiciliares; c) ao concluir um “caso”, emite-se um relatório final a ser anexado ao prontuário; d) a equipe técnica deve elaborar um relatório sobre um "caso" quando solicitada por alguma instituição (como a escola, a delegacia, dentre outras). Tendo como responsáveis por sua emissão a equipe técnica e os educadores sociais, os relatórios acontecem através de relato escrito, impresso, assinado, carimbado e protocolado e são materializados em um processo descritivo, analítico e, por vezes, opinativo ${ }^{13}$ sobre o caso de abuso sexual em questão.

Em se tratando de um pedido expresso de outras instituições, para se fazer um relatório, assistentes sociais e psicólogas costuma-

${ }^{13}$ Há relatórios em que a equipe técnica acaba emitindo uma opinião sobre o caso a pedido de outros órgãos, mas são situações pontuais. vam realizar uma visita domiciliar. Nela, com intuito levantar elementos sobre a situação, as técnicas vão munidas de um roteiro de entrevista, baseada em seus conhecimentos sobre o “caso". A visita é conduzida a depender da competência teórica das profissionais (formação, abordagem político-teórico-metodológica, capacitações etc.), experiências prévias e informações do prontuário. Às vezes, leva-se perguntas anotadas a fim de tocar em todas as questões que entenderem ser fundamentais para o "caso" e tudo é registrado. Percebemos, por exemplo, que as assistentes sociais costumam ter um caderno no qual é anotado todo e qualquer atendimento realizado, inclusive entrevistas. No processo de entrevista, interessa às técnicas conhecer melhor o usuário, levantar dados socioeconômicos, conhecer o território onde fica a residência, observar e apreender informações sobre a dinâmica familiar, saber se a criança/adolescente continua sob o mesmo teto do agressor (quando necessário), identificar possíveis violências e necessidades que o usuário está submetido etc. É importante destacar que esse processo não tem como objetivo levantar provas sobre o crime e as técnicas não têm acesso nenhum a informações da investigação e/ou do processo criminais. Depois, é elaborado um documento baseado em todas as informações produzidas tanto na visita quanto no conjunto de atendimentos realizados ao longo do tempo. Eis o relatório.

Segundo informações, não há um modelo institucionalizado para relatórios no CREAS. Todavia, existem alguns elementos fundamentais como, por exemplo, o cabeçalho com informações gerais da instituição - nome, endereço, telefone -, o título Relatório, quem solicitou e quem emitiu o relatório, número de protocolo. Estes são os elementos pré-textuais que identificamos. Quanto ao texto propriamente dito, espera-se que a escrita tenha uma linguagem técnica (ou seja, com termos acadêmicos e específicos da formação das técnicas), enfoque a questão fundamental do “caso” e respondendo claramente à solicitação do órgão que pediu o documento. 
Em geral, os relatórios iniciam o texto descrevendo: 1) a solicitação da autoridade destinatária (juíza, delegada, ou outros); 2) a intervenção realizada pelo CREAS através do acompanhamento psicossocial; 3) o território no qual o usuário reside (se mora na região urbana/rural, favela, zona violenta, bairro nobre etc); 4) situação socioeconômica (renda familiar, benefícios do governo, número de pessoas na residência, casa própria/alugada/cedida/invadida, quem é dependente/mantedor); 5) a situação escolar da criança/adolescente; 6) a organização familiar e as relações comunitárias estabelecidas pelo usuário(como se relaciona com as família, vizinhos, escola, se o usuário (ou algum familiar) é dependente de álcool e/ ou outras drogas, se o agressor mora na mesma casa (ou próximo) da vítima); 7) ver se a criança está sendo bem cuidada (higiene, fome, violências, exposição a doenças e situações inadequadas); 8) saúde psicológica da criança/ adolescente (depressão, ansiedade etc.) . De acordo com as assistentes sociais e psicólogas, o objetivo não é criminalizar a pobreza, mas descrever em que condições a criança vive, se ela está ainda em situação de violência e como a situação de violência repercutiu na vida dela. Ao final, se for o caso, as técnicas podem (mas pouco o fazem) recomendar às autoridades quanto a providências a serem tomadas, construindo uma argumentação fundamentada no aporte teórico de cada disciplina (psicologia ¿ี ou serviço social). Vale ressaltar que as técnicas entrevistadas afirmaram categoricamente que não é de interesse delas emitir um docu¿ mento pericial no qual se ateste se houve (ou ก não) o abuso sexual, pois isso seria trabalho $\dot{\sim}$ de psicólogos e assistentes sociais que ocupam लే cargos de peritos criminais.

Os relatórios têm caráter sigiloso e, portanto, só podem ser lidos por quem é de direito. Além disso, devido a questões relativas aos códigos de ética profissionais, apenas a assistente social pode emitir relatório social no CREAS. Já as psicólogas devem descrever, analisar e emitir opinião acerca dos assuntos (estados psicológicos) pertinentes à área de psicologia. Isso traz mais um problema no trabalho interdisciplinar, já que não há claramente previsto (pelo menos não no entendimento das técnicas entrevistadas) como produzir documentos de forma interdisciplinar. Portanto, como solução prática ao problema, as técnicas afirmaram que cada uma faz e assina sua parte do relatório. Depois juntam em um único documento, que - devidamente impresso, assinado, carimbado e datado - é enviado à instituição destinatária via "motoboy".

\section{CONCLUSÃO}

Este artigo teve como objetivo mostrar como acontece o processo de atuação (enactment) do abuso sexual infantojuvenil enquanto "problema social" em um CREAS de Fortaleza. Iniciamos nossa análise tomando como pressuposto a ideia de que as práticas realizadas no âmbito do CREAS são atuadas através não somente das determinações estruturais do sistema de assistência social, mas também da manipulação de materiais heterogêneos e da criação de estratégias que fazem com que o abuso sexual infantojuvenil enquanto "problema social" exista ou desapareça nos dados oficiais.

Vimos que para esse processo ser bem-sucedido - a ponto de desencadear ações públicas de enfrentamento ao "problema" - faz-se necessário um acontecimento de ordem sexual envolvendo crianças/adolescentes e adultos. Essa experiência pode (ou não) envolver vínculos familiares, comunitários, afetivos e, geralmente, é estabelecida e mantida em segredo. Este, por vezes, é rompido, o que desencadeia novos mecanismos de manutenção da situação e/ou uma denúncia. Caso haja uma denúncia, esta gera uma notificação, ou seja, o reconhecimento oficial de algo, que oficialmente não deveria ter acontecido, aconteceu. Já a notificação acontece através de uma série atos - análises, registros, enumerações, encaminhamentos, telefonemas, elaboração e circulação de 
documentos, ${ }^{14}$ quantificação - alimentam as estatísticas de ocorrência do "problema" formando um banco de dados, sendo sua publicização feita mensalmente através do site oficial do Governo do Estado do Ceará em um quadro estatístico e em relatórios de gestão.

O abuso sexual infantojuvenil, assim, se torna um "problema social" através da manipulação das informações produzidas e a circulação de documentos. É um fenômeno parecido com o de "desaparecimento civil" analisado por Ferreira (2013, p. 40): “as experiências [...] vividas são encaradas por todos esses agentes como manifestações particulares de um só fenômeno”. Já como “problema social”, o abuso sexual infantojuvenil é performado de, pelo menos, duas formas: a) a publicização, com a quantificação e a publicação de estatísticas de casos; b) o acompanhamento, que se materializa na intervenção estatal de caráter psicossocial e jurídico diante dos efeitos desencadeados não somente por experiências pessoais (e familiares), mas também por sua publicização.

A intervenção estatal diante de casos registrados de abuso sexual infantojuvenil é realizada através de uma série de práticas técnicas como acolhimento, escuta, entrevista, visitas domiciliares, registros de denúncias, preenchimento de fichas, elaboração e circulação documentos, além do uso de computadores, telefones, modelos estatísticos, automóveis, papeis, cadernos, canetas, tintas, brinquedos, pessoas. A manipulação destes e outros elementos visa - através de registro, descrição, escolhas - chamar a atenção para a existência de um "problema" e uma busca por sua solução. Para tanto, identificamos aqui uma necessidade de repetição de "marcas significativas" (Vianna, 2014) como, por exemplo, número do caso, identificação dos usuários, descrição do acontecimento, descrição de sintomas e sinais que venham a corroborar (ou não) com a descrição do acontecimento tido

${ }^{14}$ Que aqui são mais do que uma representação gráfica de um fato. São agentes mediadores, transformadores e/ ou produtores de relações cujos desdobramentos desencadeiam diversos efeitos. socialmente como problemático. Trata-se da atuação da "força de verdade pela repetição" (Vianna, 2014, p. 47) que, junto à criação e a manutenção de arquivos, é característico da moderna burocracia brasileira (Vianna, 2014; Ferreira, 2013). Neste sentido, esse processo, assim como a notificação, é fundamental para performance bem-sucedida do abuso sexual infantojuvenilenquanto "problema social": se a atuação (enactment) do abuso sexual infantojuvenilseguir os desdobramentos e trâmites esperados, se a manipulação de determinados elementos for bem-sucedida e se houver a publicização dos dados, forma-se um "problema social”. E, assim, o “caso” acontece.

Observando a produção e o atendimento dos "casos" de abuso sexual infantojuvenil, pudemos perceber que os processos relativos à burocracia tomam a maior parte do tempo dos trabalhadores do CREAS. "A gente faz muito documento [...]. Muita coisa, às vezes, tem dia, assim, que a gente fica até presa. Em relação a essa questão de... como a gente ter muita denúncia, tem muita resposta de ofício, de relatórios, pra onde é que vai, o que é que tem que fazer", revelou-nos a então coordenadora. Por outro lado, o CREAS analisado é responsável por atender metade dos casos denunciados em Fortaleza, o que traz uma alta demanda para um número restrito de profissionais. Além disso, a grande rotatividade de trabalhadores devido ao vínculo empregatício precarizado e baixos salários e a dificuldade na compreensão sobre as atribuições de cada especialidade (e os desafios de um trabalho interdisciplinar) comprometem o pleno acompanhamento dos usuários.

Em sua dissertação, Costa (2013) mostrou que crianças e adolescentes esperavam dos serviços públicos de atendimento psicossocial uma atenção maior a suas dores, algo que não encontraram nas instituições que frequentaram. Este artigo trouxe algumas pistas que podem explicar esse desencontro. A situação dos serviços especializados de atendimento a vítimas de abuso sexual infanto-juvenil em Fortaleza, especialmente o CREAS, é complexa 
e envolve não apenas questões estruturais, mas também práticas cotidianas burocráticas que podem explicar também o alto índice de evasão nos atendimentos (que no CREAS chegavam a 90\%). Enquanto o produzir documentos toma boa parte do tempo dos profissionais, noções como as de atenção e cuidado praticamente não apareceram durante a pesquisa.

Recebido para publicação em 07 de outubro de 2020 Aceito para publicação em 13 de setembro de 2021

\section{REFERÊNCIAS}

ALAGOAS. Secretaria de Estado da Assistência e Desenvolvimento Social. Glossário na área da assistência social e planejamento. Maceió, 2010. Disponível em: http://www.assistenciasocial.al.gov.br/sala-de-imprensa/ arquivos. Acesso em: 05.03. 2017.

BELO HORIZONTE. Prefeitura Municipal. Secretaria Municipal Adjunta de Assistência Social. Dicionário de termos técnicos da assistência social. Belo Horizonte: ASCOM, 2007. 132 p.

CORDEIRO, Mariana Prioli; SATO, Leny. Psicologia na política de assistência social: trabalho em um "setor terceirizado". Estud. psicol. (Campinas), v. 34, n. 1, p. 4152, jan./mar.2017.

COSTA, I. M. M. da. “Caderno de segredos”: trajetórias de vida marcadas pelo abuso sexual incestuoso. 2013. Dissertação (Mestrado em Políticas Públicas e Sociedade) - Centro de Humanidades, Universidade Estadual do Ceará, Fortaleza.

FERREIRA, L. C. de M. Apenas preencher papel: reflexões sobre registros policiais de desaparecimento de pessoa e outros documentos. Mana, v. 19, n. 1, p. 39-68, abr. 2013.

FLORES, A. P. O Papel do Advogado no Sistema Único de Assistência Social (Suas): algumas reflexões contemporâneas necessárias para a sua efetivação. p. 1-20, [2015]. Disponível em: <https://craspsicologia.files.wordpress.com/2015/02/ artigo-o-papel-do-advogado-no-suas.pdf > . Acesso em: 07.03. 2017.

ปิ GERBER, L. M. L. Oficina de serviço social: elaboração จ de relatórios e laudos. 2011. Disponível em: < http:// ^ www.amavi.org.br/sistemas/pagina/setores/associal/ o arquivos/2011/Texto-Oficina-de-Servico-Social$\rightarrow$ Elaboracao-de-Estudos-e-Parecer-Social.pdf $>$. Acesso em: \%ै 30.03. 2017
HABIGZANG, L. F. et al. Abuso sexual infantil e dinâmica familiar: aspectos observados em processos jurídicos. Psicologia: teoria e pesquisa, v. 21 , n. 3 , p. 341-348, set./ dez. 2005.

HADLER, O. H.; GUARESCHI, N. M. F. Highlander entre o SUAS, a psicologia e os direitos humanos: novas interfaces de subjetivação. In: CRUZ, L. R; GUARESCHI (orgs.). $O$ psicólogo e as políticas públicas de assistência social. Petrópolis: Vozes, 2012. p. 176-194.

INGOLD, T. Da transmissão de representações à educação da atenção. Educação, Porto Alegre, v. 33, n. 1, p. 6-25, jan./abr. 2010. Disponível em: <http://revistaseletronicas.pucrs.br/ojs/ index.php/faced/article/view/6777 > . Acesso em: 11.10. 2019.

LATOUR, B. A esperança de Pandora: ensaios sobre a realidade dos estudos científicos. São Paulo: UNESP, 2002.

LATOUR, B. Como falar do corpo? In: Objectos impuros: experiências em estudos sobre a ciência. Porto: Edições Afrontamento, 2008. Disponível em: <http://www. bruno-latour.fr/sites/default/files/downloads/77-BODYNORMATIVE-POR.pdf>. Acesso em: 19.03. 2018.

LIMA, J. de S.; DESLANDES, S. F. A notificação compulsória do abuso sexual contra crianças e adolescentes: uma comparação entre os dispositivos americanos e brasileiros. Interface comun. saúde educ., v. 15, n. 38, 13p., jul./set. 2011.

MOL, A. The Body Multiple: ontology in medical practice. Durham and London: Duke University Press, 2002.

TEIXEIRA, M. da G. et al. Seleção das doenças de notificação compulsória: critérios e recomendações para as três esferas de governo. Informe epidemiológico do SUS, v. 7, n. 1, p. 7-28, mar. 1998.

UNICEF United Nations Children's Fund. Sexual Violence: Not limited to girls. In: . Hidden in Plain Sight: A statistical analysis of violence against children. UNICEF, New York, 2014. p. 60-93.

VALENZUELA, F. A.; ZINCKE, C. R. Cómo los maltratos se transforman en "violencia intrafamiliar": el recorrido de la performatividad. Revista de Estudios Sociales, n. 51, p. 213-226, jan./mar. 2015. Disponível em: <http://search. proquest.com/openview/185b95e5d0c49db6a6b8db9554f da666 $/ 1$ ?pq-origsite $=$ gscholar\&cbl $=38989>$. Acesso em: 30.03. 2017 .

VIANNA, A. Etnografando documentos: uma antropóloga em meio a processos judiciais. In: CASTILHO, S. R. R.; LIMA, A. C. de S.; TEIXEIRA, C. C. Antropologia das práticas de poder: reflexões etnográficas entre burocratas, elites e corporações. Rio de Janeiro: Contra capa; FAPERJ, 2014. p. 43-70. 


\section{CHILD SEXUAL ABUSE AS A "SOCIAL PROBLEM” IN FORTALEZA, CEARÁ}

\author{
Irlena Maria Malheiros da Costa \\ César Barreira \\ Luis Silva Barros \\ Jackeline S. Jerônimo de Souza
}

\section{ABUS SEXUELS CHEZ L'ENFANT COMME “PROBLÈME SOCIAL” À FORTALEZA, CEARÁ}

\author{
Irlena Maria Malheiros da Costa \\ César Barreira \\ Luis Silva Barros \\ Jackeline S. Jerônimo de Souza
}

In this article, we describe and analyze the process of enactment of child sexual abuse as a "social problem", which is processed by the Resource Network to Children and Adolescents Victims of Sexual Violence in Fortaleza, Ceará (Rede). Practices and experiences, whether collective or individual, that mobilize and articulate multiple elements capable of producing "cases of sexual abuse" have been observed at one of the Specialized Reference Centers for Social Assistance (CREAS). The term sexual abuse of children and adolescents is based on the premise that the sex relationships between adults and children is unacceptable and, therefore, abusive, given the adult's goal of achieving his or her own sexual pleasure. However, Rede may only officially characterize a case of sexual abuse if the case is denounced, analyzed, typified, enumerated and accounted for on a dossier of every assistance made backed-up by specialized documentary records capable of technically reporting the incident.

KeYwords: Sexual abuse. Social problem. CREAS. Enactment.
Dans cet article, nous décrivons et analysons le processus d'action (mise en acte) des abus sexuels chez l'enfant comme un "problème social" auquel doit faire face le réseau de soins pour enfants et adolescents victimes de violences sexuelles à Fortaleza, Ceará (Réseau). Des pratiques et des expériences ont été observées, qu'elles soient collectives ou individuelles, qui mobilisent et articulent de multiples éléments capables de produire des "cas d'abus sexuels" dans un Centre de Référence Spécialisé d'Aide Sociale (CREAS) de la ville. Le terme abus sexuel part du principe que l'union des sexualités des enfants et des adultes est inacceptable et, par conséquent, abusive du fait que le but de l'adulte est d'obtenir son propre plaisir sexuel. Cependant, pour être considéré comme abus sexuel dans le Réseau, il est nécessaire que la situation sexuelle soit révélée, dénoncée, analysée, typifiée, énumérée et comptabilisée, formant un dossier avec des archives documentaires spécialisées, capable de rapporter techniquement l'événement.

Mots CLÉs: Abus sexuels. Problème social. CREAS. Promulgation.

Irlena Maria Malheiros da Costa - Pós-doutoranda no Programa de Pós-Graduação em Sociologia da Universidade Federal do Ceará (Bolsista PNPD/CAPES). Especialista em Saúde Pública (UECE). Doutora em Ciências Sociais pelo Programa de Pós-Graduação em Ciências Sociais da Universidade Federal da Bahia (UFBA). Autora do artigo: Era eu dizendo uma coisa e todo mundo dizendo outra: a constituição de vítima de "abuso sexual infantojuvenil" na justiça criminal, publicado em 2016.

César Barreira - Professor Titular em Sociologia do Departamento de Ciências Sociais e do Programa de Pós-Graduação em Sociologia da Universidade Federal do Ceará (UFC). Diretor do Colégio de Estudos Avançados da UFC. Coordenador do Laboratório de Estudos da Violência (LEV/UFC). Pesquisador do CNPq (nível I-A), líder do Grupo de Pesquisa em Poder, Violência e Cidadania do CNPq. Especialista em Metodologia da Pesquisa Social pela Universidade Federal do Ceará (1973). Doutor em Sociologia pela Universidade de São Paulo (1987). Destaque para a obra: Cotidiano despedaçado: cenas de uma violência difusa, Pontes Editora, 2008.

Luis Silva Barros - Pós-doutorando no Programa de Pós-graduação em Engenharia Civil e Ambiental da UFC. Graduado em Economia. Universidade de Brasília, UNB, Brasil. Mestre em Latin American Studies. University of Arizona, ARIZONA, Estados Unidos. $\mathrm{PhD}$ em Antropologia pela University of Arizona e Doutor em Sociologia pela Universidade Federal do Ceará. Destaque para o artigo: Uma sociedade capitalista sem os valores utilitários do egoísmo racional: o Brasil no início do século XXI, publicado na Revista Brasileira de Sociologia, v. 07, p. 235-254, 2019.

Jackeline S. Jerônimo de Souza - Mestranda no Programa de Pós-Graduação em Ciências Sociais da Universidade Federal da Bahia (UFBA). Graduada em Ciências Sociais pela UFBA. Autora da comunicação "Encontros na cura: relações entre pesquisadores e animais na produção de antídoto, na $8^{\text {a }}$ Conferência Latinoamericana y Caribeña de Ciências Sociais, em 2018. 
